\title{
Suitability of Substrate for Laboratory Studies with the Subterranean Termite Reticulitermes grassei Clément (Isoptera: Rhinotermitidae)
}

\author{
P GALLARDO, AM CÁRDENAS, R MURILLO \\ University of Córdoba, Campus Rabanales, Córdoba, Spain
}

\section{Article History}

\section{Edited by}

Astrid Kleinert, USP, Brazil

Received 27 January 2016

Initial acceptance 16 March 2016

Final acceptance 21 June 2016

Publication date 15 July 2016

\section{Keywords}

Reticulitermes grassei,

Rhinotermitidae, Suitability of

substrate, Termites survival rate.

\section{Corresponding author}

Ana M Cárdenas Talaverón

Department of Zoology,

Campus Rabanales, E-14071,

University of Córdoba, Spain

E-Mail: ba1cataa@uco.es

\begin{abstract}
Two substrates, sand and vermiculite, were tested in rearing laboratory experiments with Reticulitermes grassei at different culture periods $(2,4$ and 6 weeks). Although information is available regarding procedures to keep species of Reticulitermes in lab, none of them is referred to the Mediterranean termite $R$. grassei. The suitability of substrate was assessed in terms of survival of termites. No statistically significant differences were obtained in the survival rate in the experiments with sand and vermiculite when short-time duration tests are performed, concluding that it seems to be indifferent using any of these substrates for shorter test than 8 weeks.
\end{abstract}

Reticulitermes grassei Clément is a subterranean termite species native to the northern, western and southern of the Iberian Peninsula and the southern-west France (Clement et al., 2001). Like other subterranean termites, R. grassei colonises both natural and urban environments. In human habitats, it causes damage affecting all type of constructions and represents a major pest problem (Gaju et al., 2002) because of its wide-ranging biology and the lack of implementation of effective treatments (Alcaide, 2010). In most Iberian forests $R$. grasse $i$ is very common but it has never been considered as a pest. Nevertheless, Gallardo et al. (2010) described lesions in cork oaks (Quercus suber L) as consequence of the feeding activity of these insects and indicated that nests and foraging areas appeared to be associated with sites having a high abundance of cork oaks (Cárdenas et al., 2012).

In a current research addressed to investigate the feeding response of $R$. grassei to different oak woods, the question of selecting the most suitable substrate for laboratory studies with this species prompted a prior essay to elucidate which of the two most frequently substrates on laboratory rearing species of Reticulitermes, sand and vermiculite (Haverty, 1979; Haverty \& Howard, 1981; Perkin, 2012; EN 118, 2013), was more adequate in the particular case of $R$. grassei. In order to obtain successfully results on bioassays, it is crucial to know the optimal conditions to keep the selected species of termite, not only as far as the temperature and moisture requirements are concerned, but also the suitability of the substrate (Lenz, 2005).

Research done on this subject (Haverty, 1979; Fougerousse, 1973; Lenz, 2005; Gaju et al., 2010) suggests that both vermiculite (laminar aluminium-iron-magnesium silicate) and sand, are suitable substrates for experimenting with Reticulitermes species, but none of these surveys deals with R. grassei. For this species, Gaju et al. (2010) conducted bioassays to measure the effectiveness of different termiticides using vermiculite as substrate; however, other researchers recommend sand as preferable substrate (Nobre et al., 2007; EN 118, 2013). Research aimed to elucidate which of recommended substrates is, really, the most suitable for laboratory studies with $R$. grassei are necessary in order to optimize the results of rearing experiments on this species of subterranean termite. 
Similar studies to test the suitability of substrate for laboratory essays for other species of Reticulitermes (R. flavipes Kollar and $R$. virginicus Banks) have been conducted by Haverty (1979). However, there are no studies analyzing this aspect in the case of $R$. grassei. This research has been addressed to test the suitability of both substrates in short duration tests with $R$. grassei.

Termites used on this study were collected in April 2014 from the surrounding of Sta. $\mathrm{M}^{\mathrm{a}}$ de Trassierra (Central Sierra Morena Mountains; southern Iberian Peninsula). The oak fragments of timber in which the insect were found were transported to the laboratory in plastic perforated containers. Once there, the termites were manually and carefully extracted. The insects used in these experiments were undifferentiated larvae (workers) of at least the third stage.

Two experiments were performed to determine the suitability of the substrate (Haverty, 1979; Ho \& Kirton, 2007). For each experiment, 15 rearing containers measuring $18 \times 15 \times 7 \mathrm{~cm}$ were used. These containers corresponded to an experimental design with three treatments (of 2, 4 and 6 weeks duration) and 5 replications each.

As humidity is a decisive factor in the survival of these insects, the proportions of water/substrate used for these experiments were: 1 volume of water to 4 volumes of sand, and $3 \mathrm{ml}$ of water to $1 \mathrm{~g}$ of vermiculate, proportions recommended in literature for Reticulitermes species (Nobre et al., 2007; Munizaga, 2007; Munizaga et al., 2008; Arinana et al., 2012; EN 118, 2013).

Eight sapwood blocks (approximately $2 \times 2 \times 1 \mathrm{~cm}$ in size) of pine (Pinus pinea L.) were provided as food. The wood of pine is considered the most adequate for laboratory studies with termites (Perkins, 2012; Smythe \& Carter, 1970).

A total of 150 termite workers randomly selected were introduced into each container, which were kept in a rearing chamber in permanent darkness at a constant temperature of $26 \pm 1^{\circ} \mathrm{C}$ and at $80 \pm 5 \%$ relative humidity. After 2,4 and 6 weeks, the sapwood blocks were removed and the surviving termites were censused. The survival rate was estimated as percentage of surviving workers found for each treatment (Table 1).

Table 1. Survival rate (\%), survival rate mean $(\overline{\mathrm{X}})$ and Standard Deviation (SD) of five replications of each treatment (T1, T2 and T3: 2, 4 and 6 weeks duration, respectively) for the substrates tested (vermiculite and sand).

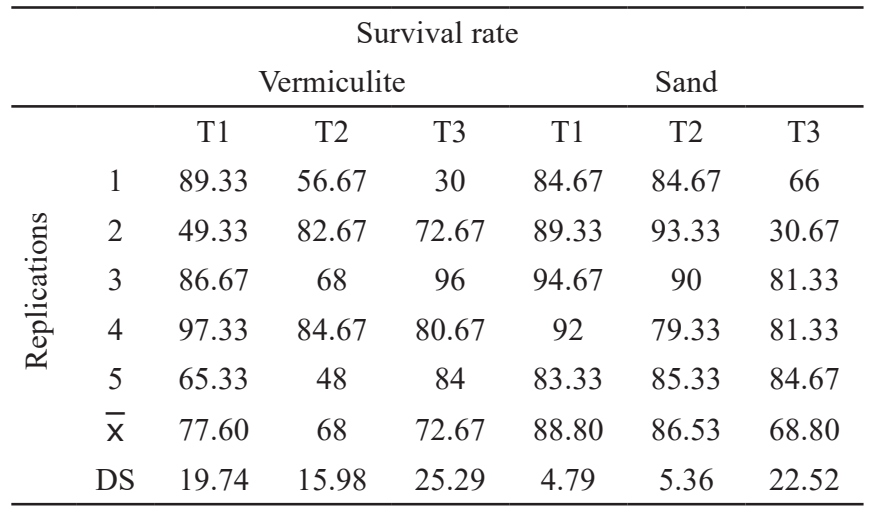

To jointly analyse the results and to elucidate possible interaction between the variables substrate and time, a Factorial ANOVA was performed using the SPSS statistical software (SPSS 20.0, 2011).

The results of the statistical analysis are displayed on Table 2. From this, it could be observed that the Factorial ANOVA did no find significant differences between variables, or in their interaction. That's to say, the survival rate of the different treatments of the experiment with vermiculite does no vary significantly from those obtained in the experiment using sand as substrate.

However, if the values of the survival rate in the two experiments are examined (Table 1), it can be observed that in sand this value decreases over time, and that the worst results are obtained after six weeks exposure (but lacking of statistical significance). This trend has not been observed in vermiculite, and could be related with the moisture level, because the sand has a minor water-holding capacity throughout time that vermiculite.

Our results are consistent with those provided by Haverty (1979) for closer species as R. flavipes and $R$. virginicus, who suggested that it seems to be indifferent the use of vermiculite or sand as substrate for shorter test than 8 weeks.

Nevertheless, in experiments of longer duration (12 weeks or more) performed with other Reticulitermes species, the use of vermiculite resulted to be the most appropriate substrate (Haverty, 1979). More research is necessary in order to know the response to the kind of substrate of $R$. grassei, in long-term tests.

Table 2. Results of the Factorial ANOVA of comparison of survival rates between the variables substrate, time of treatment, and their interaction. $P$ : probability for $\alpha=0.05 ; \mathrm{F}$ : values of Factorial ANOVA. Dependent variable: survival rate; $R^{2}=0.212$ (Adjusted $\left.\mathrm{R}^{2}=0.048\right)$.

\begin{tabular}{lcc}
\hline & \multicolumn{2}{c}{ Statistics values } \\
\hline Variable & $\mathrm{F}$ & $P$ \\
Substrate & 1.815 & 0.191 \\
Time & 1.266 & 0.300 \\
Interaction substrate-time & 1.061 & 0.362 \\
\hline
\end{tabular}

\section{Acknowledgements}

This research has been financially supported by ACUAES (Ministry of Agriculture, Food and Environment, Government of Spain) and by Ingeniería y Gestión del Sur, S.L. (Grupo IG-IPA).

\section{References}

Alcaide, M.E. (2010). Estudio del control integral de una plaga urbana de termitas en el sur de España. Dissertation, Universidad de Córdoba, España. 
Arinana, L., Tsunoda, K., Herliyana, E.N. \& Hadi, Y.S. (2012). Termite-susceptible species of wood for inclusion as a reference in Indonesian standardized laboratory testing. Insects, 3: 396-401. doi: 10.3390/insects3020396.

Cárdenas, A.M., Moyano, L., Gallardo, P. \& Hidalgo, J.M. (2012). Field activity of Reticulitermes grassei (Isoptera: Rhinotermitidae) in oak forests of the Southern Iberian Peninsula. Sociobiology, 59: 493-509. doi: 10.13102/sociobiology.v59i2613.

Clément, J.L., Bagnères, A.G., Uva, P., Wilfert, L., Quintana, A., Reinhard, J. \& Dronnet, S. (2001). Biosystematics of Reticulitermes termites in Europe: morphological, chemical and molecular data. Insectes Sociaux, 48: 202-215. doi: 10.1007/PL00001768.

EN 118 (2013). Wood preservatives: Determination of preventive action against Reticulitermes species (European termites) (laboratory method). European Committee for Standardization, BSI Standards Publication, CEN-CENELEC, Brussels, Belgium.

Fougerousse, M. (1973). Some aspects of laboratory and field testing methods of antitermite wood preservatives. Holzforsch, 27(4): 137-142. doi: 10.1515/hfsg.1973.27.4.137.

Gaju, M., Notario, M.J., Mora, R., Alcaide, E., Moreno, T., Molero, R. \& Bach, C. (2002). Termite damage to buildings in the province of Córdoba, Spain. Sociobiology, 40: 75-85.

Gaju, M., Moyano, L., Alcaide, E., Patiño, C., Diz, J., Nunes, L., Bach, C. \& Molero, R. (2010). Laboratory study of fipronil baits against Reticulitermes grassei (Isoptera: Rhinotermitidae). Proceeding of $41^{\text {st }}$ Annual Meeting the International Research group on wood protection, Biarritz, France.

Gallardo, P., Cárdenas, A.M. \& Gaju, M. (2010). Ocurrence of Reticulitermes grassei (Isoptera: Rhinotermitidae) on cork oaks in the southern Iberian Peninsula: identification, description and incidence of the damage. Sociobiology, 56: 675-687.

Haverty, M.I. (1979). Selection of tunnelling substrates for laboratory studies with three subterranean termite species. Sociobiology, 4: 315-320.
Haverty, M.I. \& Howard, R.W. (1981). Production of soldiers and maintenance of soldier proportions by laboratory experimental groups of Reticulitermes flavipes (Kolar) and Reticulitermes virginicus (Banks) (Isoptera: Rhinotermitidae). Insectes Sociaux, 28: 32-39. doi: 10.1007/BF02223620.

Ho, T.H. \& Kirton, L.G. (2007). Effects of different substrates and activated charcoal on the survival of the subterranean termite Coptotermes curvignathus in laboratory experiments (Isoptera: Rhinotermitidae). Sociobiology, 50: 479-497.

Lenz, M. (2005). Laboratory bioassays with termites-the importance of termite biology. Proceeding the $2^{\text {a }}$ Conference of Pacific Rim Termite Research Group on Wood Protection, Bangkok, Thailand.

Munizaga, M.J. (2007). Estudio de alimentación y de sustancias tóxicas potenciales para Reticulitermes flavipes (Kollar) (Isoptera: Rhinotermitidae). Dissertation, University of Chile.

Munizaga, M.J., Araya, J.E., Karsulovic, T. \& Bozo, A. (2008). ¿Afecta la exposición previa a ninfas el consumo de madera de pino radiata de Reticulitermes flavipes (Kollar) (Isoptera: Rhinotermitidae)? Boletín de Sanidad Vegetal Plagas, 34: 533-536.

Nobre, T., Nunes, L. \& Bignell, D.E. (2007). Tunnel geometry of the subterranean termite Reticulitermes grassei (Isoptera: Rhinotermitidae) in response to sand bulk density and the presence of food. Insect Science, 14: 511-518. doi: 10.1111/j.17447917.2007.00180.x

Perkins, G.D. (2012). Reticulitermes feeding preference and experimental design. Dissertation, University of Georgia.

Smythe, R.V. \& Carter, F.L. (1970). Feeding responses to sound wood by Coptotermes formosanus, Reticulitermes flavipes, and $R$. virginicus (Isoptera: Rhinotermitidae). Annals of the Entomological Society of America, 63: 841-847. doi: 10.1093/ aesa/63.3.841.

SPSS Inc. (2011). SPSS 20.0 for Windows Use Manual (version 20.0). 